\title{
Synthesis of phenanthridines via a novel photochemically- mediated cyclization and application to the synthesis of triphaeridine
}

\author{
Songeziwe Ntsimango, Kennedy J. Ngwira, Moira L. Bode and Charles B. de Koning*
}

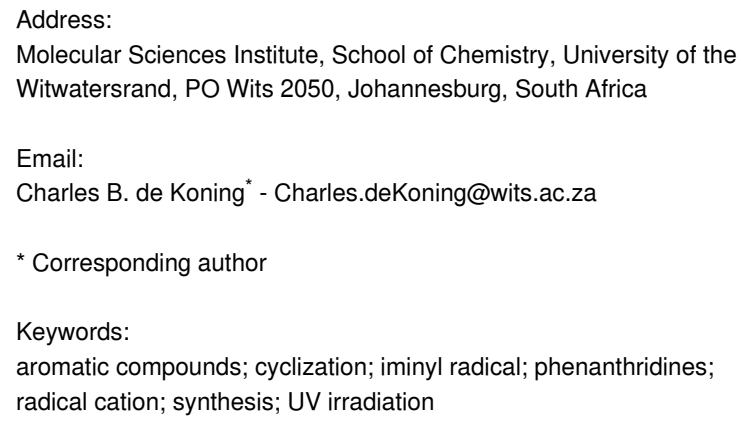

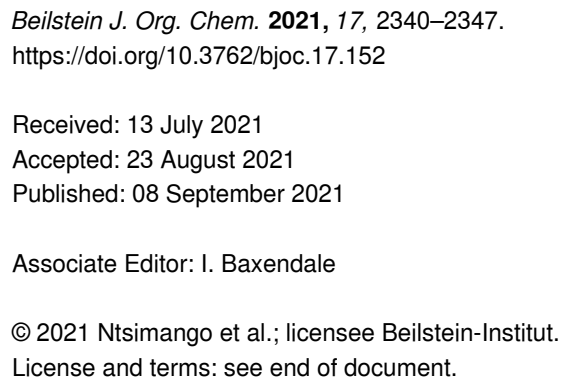

\begin{abstract}
Readily synthesized biphenyl-2-carbaldehyde $O$-acetyl oximes were exposed to UV radiation affording phenanthridines. The scope and limitations of this novel reaction were explored. For example, exposure of 2',3'-dimethoxy-[1,1'-biphenyl]-2-carbaldehyde $O$-acetyl oxime to UV radiation afforded 4-methoxyphenanthridine in 54\% yield. This methodology was applied to the synthesis of trisphaeridine to afford the product in four linear steps in an overall yield of $6.5 \%$ from 1-bromo-2,4,5-trimethoxybenzene.
\end{abstract}

\section{Introduction}

Phenanthridine derivatives have captivated synthetic chemists and biologists alike since the 1960s due to their efficient DNA binding, antitumour and antiparasitic activities [1]. Such compounds include the DNA and RNA-fluorescent marker ethidium bromide (1), the cell viability probe propidium iodide (2) and the naturally occurring antiparasitic compounds, trisphaeridine (3), decarine (4) and nortidiene (5) (Figure 1).

The importance of the phenanthridine framework has inspired the development of numerous synthetic strategies to access these compounds. These include the classical Pictet and Ankersmit pyrolysis of $N$-benzylideneaniline [2], rhodium- mediated alkyne [2+2+2] cycloaddition reactions [3], and the palladium-catalysed aerobic domino Suzuki coupling/Michael addition reaction [4]. The most attractive and common strategies to phenanthridines rely on intramolecular cyclizations of various ortho-functionalized biaryl precursors furnishing the central ring through $\mathrm{C}-\mathrm{C}$ bond formation. Indeed, this strategy has been employed for decades in reactions such as dehydrative cyclization of acyl- $O$-aminobiphenyls at very high temperatures (the Pictet-Hubert reaction and Morgan-Walls reaction) $[5,6]$, which is also reflected in modern methods, such as ionic liquid- and transition metal-catalyzed and other metal-free transformations [1]. 
<smiles>CC[n+]1c(-c2ccccc2)c2cc(N)ccc2c2ccc(N)cc21</smiles><smiles></smiles><smiles></smiles><smiles>COc1c(O)ccc2c1cnc1c3cc4c(cc3ccc21)OCO4</smiles><smiles>COc1cc2cnc3c(ccc4cc5c(cc43)OCO5)cc-2c1</smiles>

Figure 1: Biologically active phenanthridines.

A strategically diverse route to phenanthridines involves intramolecular cyclization of biaryl oximes, allowing for the formation of a new C-N bond. Such a strategy was explored by Deb and Yoshikai in the $\mathrm{Fe}(\mathrm{III})$-catalyzed intramolecular cyclization of $O$-acetyloximes (Figure 2, reaction 1). However, this transformation was limited to ketoximes and yielded only 6-substituted phenanthridines [7]. Applying photochemical conditions, Rodriguez and Walton were able to use benzaldehydes utilizing a similar intramolecular cyclization of $O$-acetyloximes to afford phenanthridines. (Figure 2, reaction 2) [8,9]. For these transformations, the reaction is thought to go via the transient iminyl radical [10]. More recently, Yu has reported the use of in situderived $O$-acyl oximes from benzaldehydes that when subjected to visible light photoredox-catalyzed cyclizations also afforded phenanthridines (Figure 2, reaction 3) [11].

Inspired by the Rodriguez and Walton approach, we sought to synthesize the nitrogen analogue of an angucycline known as phenanthroviridone 6, [12] from oxime 7 (Scheme 1). Based on the results reported by Rodriguez and Walton we envisaged that under these photochemcial conditions, intermediate 8 would be formed. Contrary to the expected results, in our labs exposure of<smiles>[R]C(=NOC(C)=O)c1ccccc1-c1ccccc1</smiles>

$\mathrm{R}=\mathrm{Me}$ or Et or $\mathrm{Ph}$<smiles>[R]ON=C([R])c1ccccc1-c1ccccc1</smiles>

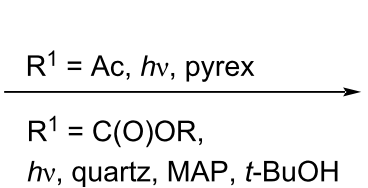<smiles>[R]c1nc2ccccc2c2ccccc12</smiles>

$\mathrm{R}=\mathrm{H}$ or $\mathrm{Me}$ or $\mathrm{Ph}$

$\mathrm{R}^{1}=\mathrm{Ac}$ or $-\mathrm{C}(\mathrm{O}) \mathrm{OR}$

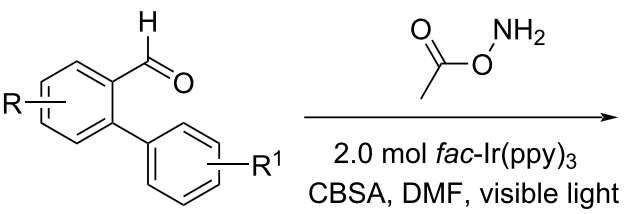

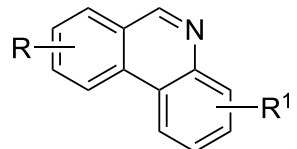

$\mathrm{R}=\mathrm{H}$ or $\mathrm{Me}$ or $\mathrm{Ph}$ or $\mathrm{Cl}$ or $\mathrm{CF}_{3}$

$\mathrm{R}^{1}=\mathrm{H}$ or $\mathrm{F}$ or $\mathrm{OMe}$

Figure 2: Synthetic routes to phenanthridines via iminyl radicals. 
<smiles>COc1cc(C)cc(/C=N/Oc2ccccc2)c1-c1cc(OC)c2c(OC)cccc2c1OC</smiles>

7<smiles>COc1cccc2c1C(=O)c1ncc3cc(C)cc(O)c3c1C2=O</smiles>

8

6<smiles>COc1cc(C)cc(C=[NH2+])c1-c1cc(OC)c2c(OC)cccc2c1OC</smiles>

9

10

11

Scheme 1: Previous unexpected synthesis of the phenanthridine framework.

oxime 7 to UV irradiation yielded phenanthridine 9 as the main product alongside the nitrile $\mathbf{1 0}$ in lower yields [13]. We hypothesized that oxime 7 undergoes a homolytic cleavage of the $\mathrm{N}-\mathrm{O}$ bond giving the iminyl radical 11 [14] followed by an intramolecular cyclization with concomitant expulsion of the ortho-methoxy group, liberating phenanthridine 9.

To the best of our knowledge, such a reaction in which the aromatic methoxy group is a leaving group resulting in the formation of phenanthridines is unprecedented. As is outlined in this paper we set out to investigate the scope and limitations of this reaction resulting in the formation of the phenanthridine skeleton. We also report on the application of this methodology to the synthesis of the simple phenanthridine natural product trisphaeridine (3).

\section{Results and Discussion}

To investigate the scope and limitations of the reaction we initially opted to prepare a number of biaryl substrates possessing one aromatic electron accepting ring possessing a variety of methoxy substituents in a range of positions. In all cases at least one methoxy substituent was positioned ortho- to the biaryl axis. The other aromatic ring had to contain an oxime ester, which would form an iminyl electron donor, as shown in Scheme 2. As illustrated substrates 13a-f were accessed using the Suzuki-Miyaura cross-coupling reaction of a variety of halogenated methoxybenzene-containing compounds with 2-(formylphenyl)boronic acids in generally good yields [15].
As a next step, the biaryl aldehydes 13a-f were converted into their corresponding oximes 14a-f in good yields as a mixture of $(E)$ and $(Z)$-isomers by reaction initally with hydroxylamine followed by acetyl chloride (Scheme 3 ).

The next step was the key photochemical ring closure to determine the scope and limitations of the novel phenanthridineforming reaction from biaryl oximes (i.e., $14 \rightarrow \mathbf{1 5}$ ). Exposure of the substrates 14a-f to UV irradiation utilizing a $450 \mathrm{~W} \mathrm{Hg}$ medium pressure lamp and through a quartz filter, afforded in most cases the phenanthridines. The first four cases, as shown in Scheme 4, resulted in the desired phenanthridines (15a-d) in varying yields, although in all cases the related benzonitriles (16a-d) were obtained.

To be effective, the desired cyclization needs a second methoxy substituent ortho- or para- to the leaving group, which in this case is an aromatic methoxy substituent.

Based on these results we suggest two possible mechanisms for these transformations. Both would proceed through an intermediary electron donor iminyl radical. In fact, iminyl radicals have been identified and studied by EPR spectroscopy in a number of related processes involving oxime derivatives [14]. As an example utilizing substrate 14d, intermediates such as the iminyl radical 17a and the ring closed intermediate 17b (Figure 3) would allow for the stabilization of the radical by the methoxy substituent in the ortho position to the departing substituent. The methoxy substituent then presumably loses a hydrogen 


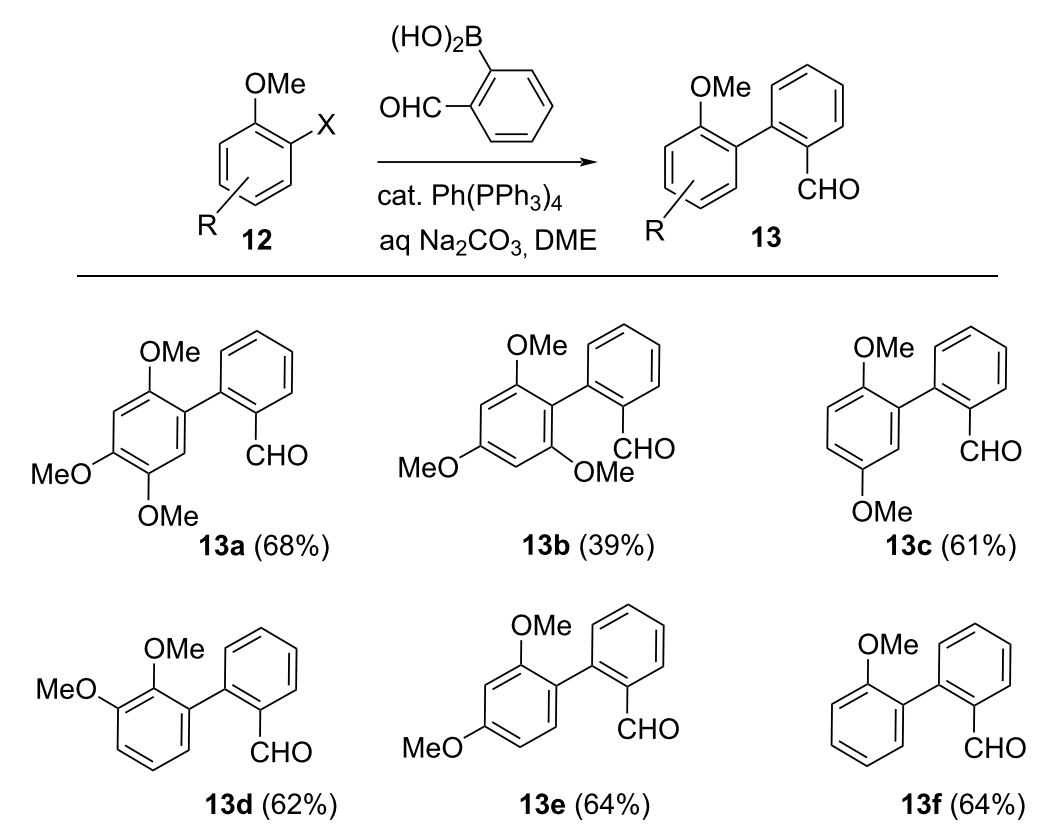

Scheme 2: Synthesis of biaryl benzaldehydes.

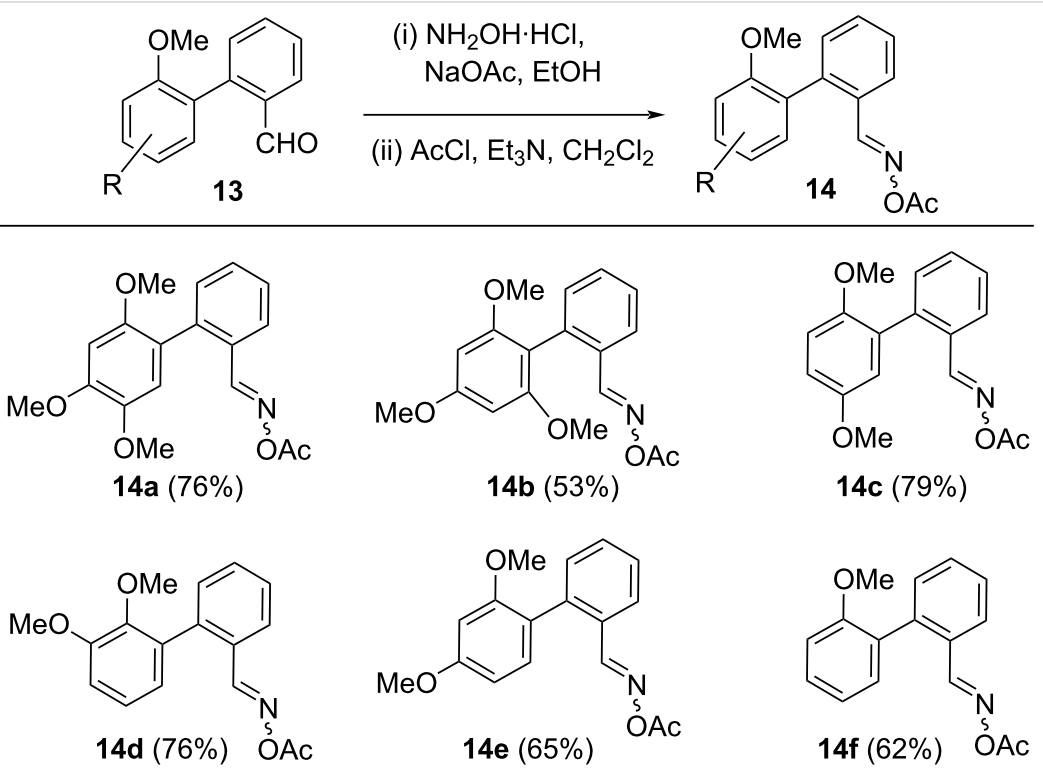

Scheme 3: Synthesis of biaryl oximes.

radical to form acetic acid and intermediate 17c. Further loss of formaldehyde would restore aromaticity and furnish the desired phenanthridine 16d.

As the aromatic substrates 14a-d contain an electron-rich aromatic ring, the second possibility is the reaction proceeds via the oxidation of the methoxy-containing aromatic ring to afford intermediate 18a. The reaction could then proceed to afford intermediate $\mathbf{1 8 b}$. Once intermediate $\mathbf{1 8 b}$ is formed an $\mathrm{H}^{+}$is abstracted by an acetate ion from the methoxy substituent again forming formaldehyde and acetic acid, along with subsequent quenching of the cation to restore aromaticity. Examples of photoredox-catalyzed cation radical accelerated reactions with the aromatic methoxy group as a leaving group have been documented [16].

Our previous research, as shown in Scheme 1, indicated that exposure of the oxime ether 7 to UV radiation resulted in the 
<smiles>COc1cc(OC)c(-c2ccccc2C#N)cc1C=NOC(C)=O</smiles><smiles>COc1cc(OC)c(-c2c(OC)cc(OC)cc2OC)c(OC)c1</smiles><smiles>COc1ccc(OC)c(-c2ccccc2/C=N/OC(C)C)c1</smiles>

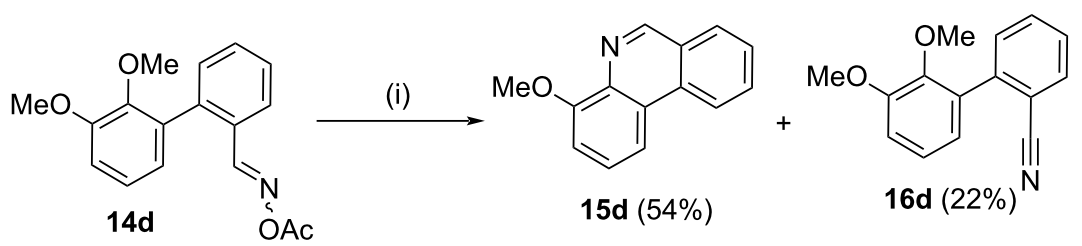<smiles>COc1ccc(-c2ccccc2C#N)c(OC)c1</smiles><smiles>COc1ccccc1-c1ccccc1C=NOC(C)C</smiles>

Scheme 4: Synthesis of phenanthridines. Reagents and conditions (i) UV irradiation (450 W medium pressure $\mathrm{Hg}$ lamp), $t$-BuOH, $3 \mathrm{~h}$.

formation of the phenanthridine 8. Attempts to synthesize the related oxime ethers from biaryl compounds $13 \mathbf{a}, \mathbf{1 3 c}$ and $13 \mathbf{e}$ with $O$-phenylhydroxylamine as reagent were not successful and only resulted in the formation of the benzonitriles 16a, 16c and 16e. Presumably, the oximes were formed but were unstable and the facile elimination of phenol took place to liberate the benzonitriles.

Finally, the use of this methodology was demonstrated to be useful for the synthesis of the natural product trisphaeridine (3) [17]. Exposure of 1-bromo-2,4,5-trimethoxybenzene (19) to
Suzuki-Miyaura coupling reaction conditions with boronic acid 20 resulted in the formation of aldehyde $\mathbf{2 1}$ (Scheme 5). Treatment of $\mathbf{2 1}$ with hydroxylamine hydrochloride and then acetyl chloride afforded oxime 22. Next was the key photochemical step. Exposure of $\mathbf{2 2}$ to UV irradiation resulted in the formation of the desired phenanthridine $\mathbf{2 3}$ in a disappointing yield of $41 \%$, together with the benzonitrile 24 . Phenanthridine $\mathbf{2 3}$ was then treated with CAN followed by zinc in acetic acid which resulted in the synthesis of trisphaeridine $(3)$ in five steps in a moderate overall yield of $6.5 \%$ commencing from 19. 
<smiles>COc1cccc(-c2ccccc2C=N)c1OC</smiles>

$17 a$<smiles>COC1C=CC=C2c3ccccc3C=NC21O[CH]COC(C)=O</smiles>

$17 \mathrm{~b}$

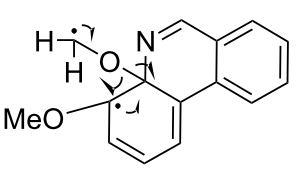

17c<smiles>CCO</smiles><smiles></smiles>

$18 \mathrm{a}$

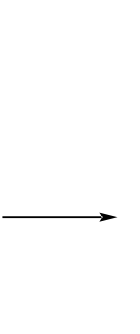

(1)

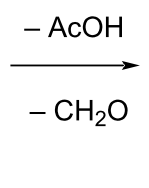

Figure 3: Two possible mechanistic routes and intermediates in the synthesis of phenanthridines.

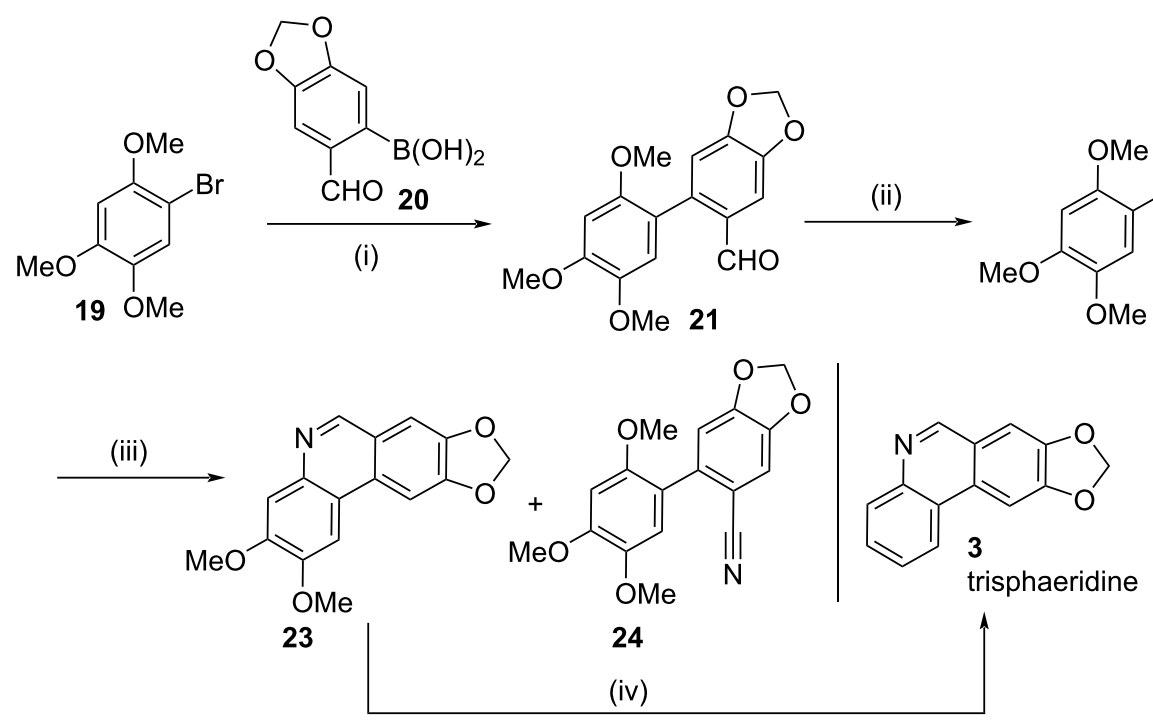

Scheme 5: Synthesis of trisphaeridine. Reagents and conditions (i) cat. $\mathrm{Pd}\left(\mathrm{PPh}_{3}\right)_{4}, \mathrm{aq} \mathrm{Na}_{2} \mathrm{CO}_{3}, \mathrm{DME}$, reflux, $\mathrm{Ar}$, overnight, $58 \%$; (ii) $(\mathrm{a}) \mathrm{NH} \mathrm{OH}_{2} \mathrm{OHCl}$, $\mathrm{NaOAc}, \mathrm{EtOH} / \mathrm{H}_{2} \mathrm{O}$ (1:1), $35{ }^{\circ} \mathrm{C}, 30 \mathrm{~min}$, (b) AcCl, pyr, rt, $3 \mathrm{~h}, 74 \%$ (for the two steps); (iii) UV irradiation, (450 W medium pressure $\mathrm{Hg}$ lamp), $t$-BuOH, rt, $1 \mathrm{~h}, 2341 \%$ and $2453 \%$; (iv) (a) $\mathrm{CAN}, \mathrm{MeCN} / \mathrm{H}_{2} \mathrm{O}(2: 1), 0{ }^{\circ} \mathrm{C}, 30 \mathrm{~min}$, (b) $\mathrm{Zn}, \mathrm{NaCl}, \mathrm{AcOH}, 150,3 \mathrm{~h}, 37 \%$ (overall for the two steps).

\section{Conclusion}

In summary, a novel UV light-mediated method for the synthesis of phenanthridines from biaryl oximes has been discovered. A key highlight includes having a methoxy substituent as the leaving group for the formation of phenanthridines. Structure-reactivity relationship studies also indicated that an orthoor para-methoxy group must be present to stabilize the incipient radical or radical cation intermediate. We propose that the reaction is proceeding by means of the initial generation of an iminyl radical that cyclizes onto the electron-rich aromatic ring or through the formation of a radical cation on the electron-rich benzene ring. Finally, the methodology has successfully been applied to synthesizing the natural product trisphaeridine.

\section{Experimental}

For general experimental procedures, please consult Supporting Information File 1.

\section{Suzuki coupling: general procedure}

To a deoxygenated $0.25 \mathrm{M}$ solution of arylboronic acid (1.2 equiv) in DME stirring under argon was added aryl bromide (1.0 equiv), $\mathrm{Pd}\left(\mathrm{PPh}_{3}\right)_{4}(10 \mathrm{~mol} \%)$ and deoxygenated $2 \mathrm{M}$ aqueous solution of $\mathrm{Na}_{2} \mathrm{CO}_{3}$ (4.0 equiv) in water. The resulting suspension was heated to reflux for $18 \mathrm{~h}$. The resulting solution was allowed to cool to room temperature and was quenched with water $(30 \mathrm{~mL})$. The solution was extracted with EtOAc $(3 \times 50 \mathrm{~mL})$. The combined organic layers were dried over 
$\mathrm{MgSO}_{4}$. The solvent was removed under reduced pressure and the resulting crude biaryl carbonyls were purified using silica gel column chromatography (using EtOAc/hexane mixtures as eluent).

Experimental details for the preparation of compounds 13a-f can be found in Supporting Information File 1.

\section{Oxime ester formation: general procedure}

To a solution of biaryl carbonyl (1.0 equiv) in $\mathrm{EtOH}(0.1 \mathrm{M})$ was added hydroxylamine hydrochloride ( 2.0 equiv) and sodium acetate (2.0 equiv). The resulting suspension was stirred under reflux for $18 \mathrm{~h}$. The contents of the flask were allowed to cool to room temperature upon which a precipitate formed. The solvent was filtered and the resulting white solid was dissolved in EtOAc and washed successively with water and brine. The organic layer was dried over $\mathrm{MgSO}_{4}$ and the volatiles were removed under reduced pressure. The resulting biaryl oximes were used without further purification.

A two-necked flask equipped with a magnetic bar and a dropping funnel was charged with a biaryl oxime (1.0 equiv), dry $\mathrm{CH}_{2} \mathrm{Cl}_{2}$ and trimethylamine (2.0 equiv). The solution was cooled to $0{ }^{\circ} \mathrm{C}$ in an ice bath and a solution of acetyl chloride (2.0 equiv) in dry $\mathrm{CH}_{2} \mathrm{Cl}_{2}(2.75 \mathrm{M})$ was added dropwise for $15 \mathrm{~min}$. The ice bath was removed and the resulting solution was allowed to slowly warm to room temperature. The reaction mixture was stirred overnight. Water $(30 \mathrm{~mL})$ was added and the layers were separated. The aqueous layer was extracted with $\mathrm{CH}_{2} \mathrm{Cl}_{2}(3 \times 30 \mathrm{~mL})$. The combined organic layer was washed with saturated $\mathrm{NaHCO}_{3}$ solution $(10 \mathrm{~mL})$ and brine $(10 \mathrm{~mL})$. The solution was dried over $\mathrm{MgSO}_{4}$ and the solvent was evaporated under reduced pressure. The resulting crude oxime esters were purified by silica gel column chromatography (using EtOAc/hexane mixtures as eluent).

Experimental details for the preparation of compounds 14a-f can be found in Supporting Information File 1.

\section{UV cyclization of oxime ester derivatives: general procedure}

A quartz UV reactor was charged with oxime ester and tertbutyl alcohol $(5 \mathrm{~mL})$ and the solution was degassed for $30 \mathrm{~min}$. The solution was then subjected to UV irradiation (450 W medium pressure $\mathrm{Hg}$ lamp, through a quartz filter) for $3 \mathrm{~h}$. The crude residue was purified by silica gel column chromatography (using EtOAc/hexane mixtures as eluent).

Experimental details for the preparation of compounds 15a-d and 16a-f as well as compounds 23 and $\mathbf{2 4}$ can be found in Supporting Information File 1.

\section{Trisphaeridine (3)}

To a solution of 2,3-dimethoxy-[1,3]dioxolo[4,5-j]phenanthridine $(\mathbf{2 3}, 63 \mathrm{mg}, 0.22 \mathrm{mmol})$ in acetonitrile $(3 \mathrm{~mL})$ was slowly added a solution of ceric ammonium nitrate $(356 \mathrm{mg}$, $0.65 \mathrm{mmol})$ in water $(1.5 \mathrm{~mL})$ at $0{ }^{\circ} \mathrm{C}$. The resulting solution was stirred at the same temperature for $30 \mathrm{~min}$ and then was quenched with ice-water $(1.5 \mathrm{~mL})$. A precipitate formed and was filtered, and washed with water. The solid was then taken up with ethyl acetate, dried over $\mathrm{MgSO}_{4}$ and the volatiles were removed under reduced pressure. [1,3]Dioxolo[4,5-j]phenanthridine-2,3-dione was obtained as a black solid (35 $\mathrm{mg}$, yield $63 \%$ ), which was used in the next step without further purification. In a high-pressure tube equipped with a stirrer bar and [1,3]dioxolo[4,5-j]phenanthridine-2,3-dione (35 mg, $0.14 \mathrm{mmol}$ ), zinc ( $37 \mathrm{mg}, 0.56 \mathrm{mmol}), \mathrm{NaCl}(33 \mathrm{mg}$, $0.55 \mathrm{mmol})$ and acetic acid $(5 \mathrm{ml})$ were added. The tube was sealed and the mixture was stirred at $150{ }^{\circ} \mathrm{C}$ for $3 \mathrm{~h}$. The reaction was neutralized with a saturated aqueous solution of sodium bicarbonate before the mixture was extracted with ethyl acetate $(3 \times 5 \mathrm{~mL})$. The combined organic layer was dried over $\mathrm{MgSO}_{4}$, and the solvent was removed under reduced pressure. The crude product was purified by column chromatography (eluent; 5-50\% EtOAc/hexane). Trisphaeridine 3 was obtained as a cream solid (19 mg, 59\%). ${ }^{1} \mathrm{H}$ NMR (400 MHz, $\left.\mathrm{CDCl}_{3}\right) \delta$ 9.08 (s, 1H, ArH), 8.36 (d, $J=8.2 \mathrm{~Hz}, 1 \mathrm{H}, \mathrm{ArH}), 8.15$ (d, $J=$ $8.1 \mathrm{~Hz}, 1 \mathrm{H}, \mathrm{ArH}), 7.89$ (s, 1H, ArH), 7.69 (t, $J=7.5 \mathrm{~Hz}, 1 \mathrm{H}$, ArH), 7.62 (t, $J=7.6 \mathrm{~Hz}, 1 \mathrm{H}, \mathrm{ArH}), 7.32$ (s, 1H, ArH), 6.16 (s, $\left.2 \mathrm{H}, \mathrm{Ar}-\mathrm{CH}_{2}\right) ;{ }^{13} \mathrm{C} \mathrm{NMR}\left(101 \mathrm{MHz}, \mathrm{CDCl}_{3}\right) \delta 151.7,151.5$, 148.2, 144.0, 130.3, 129.9, 128.0, 126.7, 124.3, 123.0, 122.0, 105.5, 101.9, 99.9 ppm [18].

\section{Supporting Information}

\section{Supporting Information File 1}

Experimental and analytical data.

[https://www.beilstein-journals.org/bjoc/content/ supplementary/1860-5397-17-152-S1.pdf]

\section{Funding}

This research was supported by the National Research Foundation (NRF grant number 105839; NRF Thuthuka, grant number TTK200304507920) Pretoria, South Africa, and the University of the Witwatersrand (Science Faculty Research Council).

\section{ORCID ${ }^{\circledR} \mathrm{iDs}$}

Kennedy J. Ngwira - https://orcid.org/0000-0003-1719-7930

Moira L. Bode - https://orcid.org/0000-0002-4153-5584

Charles B. de Koning - https://orcid.org/0000-0003-4525-5130 


\section{References}

1. Tumir, L.-M.; Radić Stojković, M.; Piantanida, I. Beilstein J. Org. Chem. 2014, 10, 2930-2954. doi:10.3762/bjoc.10.312

2. Pictet, A.; Ankersmit, H. J. Justus Liebigs Ann. Chem. 1891, 266, 138-153. doi:10.1002/jlac.18912660107

3. Li, Y.; Zhu, J.; Zhang, L.; Wu, Y.; Gong, Y. Chem. - Eur. J. 2013, 19, 8294-8299. doi:10.1002/chem.201300288

4. Ghosh, M.; Ahmed, A.; Dhara, S.; Ray, J. K. Tetrahedron Lett. 2013, 54, 4837-4840. doi:10.1016/j.tetlet.2013.06.089

5. Pictet, A.; Hubert, A. Ber. Dtsch. Chem. Ges. 1896, 29, 1182-1189. doi:10.1002/cber.18960290206

6. Morgan, G. T.; Walls, L. P. J. Chem. Soc. 1931, 2447-2456. doi:10.1039/jr9310002447

7. Deb, I.; Yoshikai, N. Org. Lett. 2013, 15, 4254-4257. doi:10.1021/ol4020392

8. Alonso, R.; Campos, P. J.; García, B.; Rodríguez, M. A. Org. Lett. 2006, 8, 3521-3523. doi:10.1021/ol061258i

9. McBurney, R. T.; Slawin, A. M. Z.; Smart, L. A.; Yu, Y.; Walton, J. C. Chem. Commun. 2011, 47, 7974-7976. doi:10.1039/c1cc12720a

10. Walton, J. C. Acc. Chem. Res. 2014, 47, 1406-1416. doi:10.1021/ar500017f

11. An, X.-D.; Yu, S. Org. Lett. 2015, 17, 2692-2695. doi:10.1021/acs.orglett.5b01096

12. Gore, M. P.; Gould, S. J.; Weller, D. D. J. Org. Chem. 1991, 56, 2289-2291. doi:10.1021/jo00007a009

13. Ngwira, K. J.; Rousseau, A. L.; Johnson, M. M.; de Koning, C. B. Eur. J. Org. Chem. 2017, 1479-1488. doi:10.1002/ejoc.201601373

14. Walton, J. C. Molecules 2016, 21, 63. doi:10.3390/molecules21010063

15. de Koning, C. B.; Michael, J. P.; Rousseau, A. L. J. Chem. Soc., Perkin Trans. 1 2000, 1705-1713. doi:10.1039/b001685n

16. Tay, N. E. S.; Nicewicz, D. A. J. Am. Chem. Soc. 2017, 139, 16100-16104. doi:10.1021/jacs.7b10076

17. Walton, J. C. Molecules 2016, 21, 660. doi:10.3390/molecules21050660

18. Harayama, T.; Akamatsu, H.; Okamura, K.; Miyagoe, T.; Akiyama, T.; Abe, H.; Takeuchi, Y. J. Chem. Soc., Perkin Trans. 1 2001, 523-528. doi:10.1039/b008683p

\section{License and Terms}

This is an Open Access article under the terms of the Creative Commons Attribution License (https://creativecommons.org/licenses/by/4.0). Please note that the reuse, redistribution and reproduction in particular requires that the author(s) and source are credited and that individual graphics may be subject to special legal provisions.

The license is subject to the Beilstein Journal of Organic Chemistry terms and conditions:

(https://www.beilstein-journals.org/bjoc/terms)

The definitive version of this article is the electronic one which can be found at:

https://doi.org/10.3762/bjoc.17.152 